\title{
REFRESHER COURSE FOR GENERAL PRACTITIONERS
}

\author{
O B E S I T Y \\ BY
}

\author{
A. H. DOUTHWAITE, M.D., F.R.C.P. \\ Physician to Guy's Hospital
}

Obesity presents social as well as physical dangers. For the first of these we are consulted largely by women. Anxious mothers bring their young daughters bulging with puppy fat derived from a free flow of buns, sweets, and other carbohydrate foods. Puberty is perhaps delayed and the parents have no doubt that it is " a question of glands." Treatment is demanded but seldom necessary. As the endocrine glands adjust themselves to the change from girlhood to womanhood. so one finds the previous rotundity giving place to the elegant figure of complete femininity. The direct influence of hormones on the loss of fat is probably negligib'e ; it is the indirect effect which is important, in that the girl's interests change direction and her desire to be attractive leads automatically to wise eating.

If corpulence persists into late adolescence the problem is more serious. By this time we have a young woman who recognizes that she is different from the others, that for her the parties and dances she attends will but emphasize her unattractiveness and produce profound depression only thinly veiled by the forced gaiety of the rotund.

The married woman who has "run to fat" after several pregnancies is assailed with fears that she will lose her attractiveness and thus her husband.

It is not often that men complain of fatness on social grounds, partly because fat young men are rare compared with women and partly because, once married, their wives practise the age-old tradition of furthering their corpulence by overfeeding. A " comfortably" obese male is alleged to be easier to live with and less likely to stray from the path of virtue.

The physical drawbacks of obesity increase in importance with age. That the expectation of life is shortened by corpulence is reflected in all insurance companies' figures. It is not so much a question of being over weight for a given height as of the abnormal distribution of excess weight. The belly measurement catches up the chest circumference, then passes it, and within a year or two that ominous bulge which hides the feet from the victim's eyes presents a signal which if disregarded may spell disaster. The increased risks to the obese of post-operative embolism and pulmonary collapse, of diabetes, hypertension, osteoarthritis, bronchitis, and various skin diseases, are well known and need no elaboration. The strain on an ageing heart even if unaffected by disease must be considerable. If a patient be resistant to a suggestion of dietetic restriction it is not a bad plan to ask him how he would feel if he carried with him all day a suitcase weighing $56 \mathrm{lb}$. $(25.4 \mathrm{~kg}$.). A parallel to this and the strain imposed on his heart can be drawn. This may not be quite fair, but the end justifies the means.

\section{Glands or Gluttony ?}

The decision whether obesity is due to an endocrine disturbance or to overeating is not in fact as important as it seems at first sight. With the exception of myxoedema all forms of obesity have to be treated by restriction of food and sometimes of salt and fluid intake. Glandular preparations administered by mouth or parenterally have, with the exception of thyroid, no effect on body weight. Thus the influence of castration in either sex, and of adrenal, pituitary, or hypothalamic disease, is not mitigated by extracts of these organs at present available. It is not imp'ied that diagnosis is not important, but merely that in relation to obesity it helps us no further.

Myxoedema is not necessarily associated with gain in weight ; in fact many myxoedematous subjects lose weight, probably because of poor appetite. It is certainly rare for obesity to be a presenting symptom. The hypothyroid woman complains rather of extreme lassitude, depression, irritability, loss of memory, and intolerable coldness. In any case the treatment is simple, though not devoid of dangers in the early stages. The more chronic the disease and the older the patient, the more important it is to give small doses of thyroid to start with. I have seen heart failure precipitated by the administration of $1 \mathrm{gr}$. $(65 \mathrm{mg}$.) of thyroid a day for five days to a myxoedematous woman of 60 . Withdrawal of the drug was fortunately followed by recovery from a critical state. Subsequently $\frac{1}{4}-\mathrm{gr}$. (16-mg.) doses daily for a week, followed by twice this amount for three weeks, led to a steady recession of her hypothyroid signs. It was then possible to give $1 \mathrm{gr}$. twice a day with safety, and full recovery ensued.

Rarities seldom come singly. In the last year I have seen two examples of Rathke's pouch tumours involving the hypothalamus. In each case the leading symptom was obesity. Both were middle-aged patients and had been fat from childhood. They had large appetites, in one amounting to gluttony. In one headaches and restriction of the visual fields, in the other unsteadiness of gait, led eventually to the correct diagnosis. Both died in spite of surgery. These examples are intended as a warning that if persistent and increasing obesity should be assoziated with headache or change of behaviour every effort should be made to exclude a neurological cause, even though the patient may have been fat for years and possessed of a voracious appetite.

\section{Common Causes of Obesity}

In general it is safe to assert that if fat is increasing the body is receiving more food than it needs. Frank gluttony is not common nowadays, and as in any case the glutton will refuse our advice it would be pointless to waste time on him. Far and away the commonest age for obesity is from 40 years on.

What are the factors which lead to a disturbance of equilibrium between intake and output? They are: (1) Repeated childbirth, no doubt at times responsible for some resetting at a higher level of the central mechanism for maintenance of weight. Often the connexion is simply that the woman is more and more tied to the house by her children. She devotes herself 
to feeding them, and is only too apt to join them at their large carbohydrate "teas" and then to keep her husband company at dinner. (2) Increasing security and more money to spend on large meals. (3) For the same reason, adding many calories to the daily food intake. by consuming strong alcoholic drinks. (4) Increasing distaste for exercise. (5) Business luncheons, often vast and alcoholic.

This middle-aged obesity is quite simple to control. The following diet will restore the body to normal proportions :

Breakfast.-Two cups of tea or coffee. One slice of toast or bread, not more than $1 \mathrm{oz}$. $(28 \mathrm{~g}$.) in weight. Butter thinly spread. Boiled or poached egg or fish (boiled or steamed) or tongue. No sausages. Fresh fruit except banana.

Luncheon.-Clear meat soup if desired. Any green vegetables, celery, salsify, asparagus ad lib. No root vegetables, rice, or macaroni. Fish or lean meat, including fowl, ad lib. (no bread crumbs or bread sauce). Fresh fruit, except banana. Half an ounce (14 g.) of cheese. Bread and butter as for breakfast. Water or soda water.

Tea.-Two cups of tea. No food.

Dinner.-As for luncheon.

Saccharin may be used for sweetening. Milk may be taken in tea, but not more than half a pint $(284 \mathrm{ml}$.) daily. One cocktail or one sherry and one glass of wine daily are permitted. Food must not be cooked in fat or oil. Worcester sauce, pepper, mustard, and vinegar are allowed. Salt to be used in cooking only.

\section{Therapeutic Obesity}

Overeating prescribed as a form of treatment often causes annoyance by virtue of ensuing obesity. I refer to the frequent meals advised to most sufferers from duodenal ulcer. The patients who keep to their instructions and drink milk between meals and at bedtime are horrified by a protuberant though now painless abdomen. The abandonment of tobacco smoking as a therapeutic measure or from caprice is well known to cause obesity be:ause of the great increase of appetite. The peptic ulcer patient can be helped by substituting for milk a protective emulsion with no food value, such as:

$$
\begin{array}{lllll}
\text { Bism. carb. } & \ldots & \ldots & \ldots & \text { gr. } 40(2.6 \text { g. }) \\
\text { Mag. trisil. } & \ldots & \ldots & \ldots & \text { gr. } 20(1.3 \mathrm{~g} .) \\
\text { Mucil. acac. } & \ldots & \ldots & \ldots & \text { q.s. } \\
\text { Tinct. aurant. } & \ldots & \ldots & \ldots & \text { min. } 10(0.6 \mathrm{ml} .) \\
\text { Aq. } \quad . . & \ldots & \ldots & \ldots & \text { ad. } \frac{1}{2} \mathrm{oz} .(14.2 \mathrm{ml} .)
\end{array}
$$

This dose to be taken in place of milk or olive oil. The antacid effect is negligible, but so is that of milk. The bismuth forms a protective pellicle and can be seen on the surface of an ulcer long after the stomach has emptied itself.

\section{Familial or Genetic Obesity}

Under this heading we have most of the really difficult cases in which overeating does not seem to play a part-the hugely fat patient afflicted by excessive weight, often from early childhood. Here also we meet localized fatness-vast buttocks and lower extremities upholding a normal torso. Again in this class we meet corpulent patients whose body weight is in part maintained by excessive retention of fluid.

In all these cases it is wise to undertake treatment only if the patient is prepared to go to bed, preferably in hospital. The dietetic measures have to be severe, the fluid restriction being irksome and often intoler- able to any patient who is ambulant and subjected to gastronomic temptation.

All these patients need a much stricter diet than that given above. Fat must be drastically reduced because of its high calorie value and because large stores are present in the patient's body. Carbohydrate is moderately reduced, though its exclusion is tolerable for a few days. Protein is the least affected, because the specific dynamic action of protein increases body metabolism. All this was quite simple in the days when food was plentiful, but the great shortage of protein foods makes scientific dieting very difficult. If the patient keeps chickens the protein is easy to get.

A pound $(0.45 \mathrm{~kg}$.) a day will be lost on the following diet :

Breakfast.-One egg and $1 \mathrm{oz}$. $(28 \mathrm{~g}$.$) of bread or toast.$ Fruit juice.

Luncheon.-One egg or $1 \mathrm{oz}$. of corned beef and vegetables as below. Fruit juice.

Dinner.-Meat soups. Lean meat or fish, $4 \mathrm{oz}$. (113 g.), and vegetables as below. Fruit juice.

Food may not be fried. Water as much as needed (unless water retention is suspected).

Vegetables: Lettuce, cucumber, spinach, asparagus, endive, celery, mushrooms, tomatoes, sprouts, watercress. cauliflower, cabbage.

Once a week the patient may have one meal of any food he likes. This is encouraging and does no harm, because his capacity for large meals falls rapidly.

Vitamins $A$ and $D$ should be supplied as liq. vitamin $A$ et D conc. (B.P.) $5 \mathrm{~min}$. (0.3 ml.) daily.

After three to four weeks on this drastic diet enough weight will have been lost to allow the patient to pass to the following diet:

Breakfast.-Fresh fruit. Egg or fish. Coffee, tea. Bread, 2 oz. (57 g.).

Luncheon.-Lean meat, fish, or fowl, $3 \mathrm{oz}$ (85 g.). Green vegetables. Fresh fruit.

Tea.-Tea.

Dinner.-Meat, fish, or fowl, $3 \mathrm{oz}$. green vegetables.

9.30 p.m.-Half a cup of orange juice.

In addition one and a half glasses of skim-milk daily (for calcium content).

Vitamins as before.

When the desired weight is attained the diet should be slowly increased by adding butter, bread, and other vegetables. With a little care it is surprisingly easy to avoid a return to obesity.

Patients who retain water and salt are often pasty in appearance but rarely show pitting oedema. They pass but little urine when up and about, but notice increased output if kept in bed. More specific waterbalance tests will show a greatly delayed output of a measured volume of fluid. If these patients do not lose weight on the above diets or if the loss is inadequate, salt should be forbidden and fluid intake limited to $1 \frac{1}{2}$ pints (850 ml.) daily. Inj. mersalyl. (B.P.), $1 \mathrm{ml}$., shou!d be given intramuscularly twice weekly. The result of the above measures should be a copious diuresis and fall of weight. The treatment can be tolerated for two to three weeks. Thereafter salt may be used in cooking but not otherwise.

\section{Starvation Treatment}

Clearly the quickest way to ensure loss of weight is to deprive the patient of all food and allow water only. As a preliminary step, when dealing with the 
more obstinate forms of obesity, this is justifiable for a few days and is suitable for young adults. Although after the first three days the craving for food rapidly diminishes, mental depression is profound. Few patients will tolerate such treatment for more than a week, and indeed prolongation of starvation beyond this point is inadvisable.

Less obvious starvation may be followed, though with reluctance, for two to three weeks. By this I mean a diet of fruit juices and lettuce only. It has a vogue among the wealthier classes, who seem to enjoy paying enormous fees for incarceration in c'inics in order to be weaned from the delights of the table.

\section{Exercise}

There is no more disappointing scheme for the reduction of fat than that which depends on vigorous exercise. The fact is that a great amount of muscular work is needed to produce appreciable weight loss. An obese patient is seldom capable of carrying this out. In any case the appetite is increased and the essential food restriction is thus made more irksome.

The main value of exercises is to tone up muscles rendered flabby from sedentary habits and fatty overlay. They play a great part in restoring abdominal girth to normal proportions and, if persisted with, certainly help to prevent recurrence of belly fat when the strict regimen is at an end. No exercises are of value unless they can be practised often and inconspicuously throughout the day. Space will not allow a full description of these, but I refer to many of those outlined in Hornibrook's well-known book Culture of the Abdomen. They are incidentally an excellent corrective of constipation.

\section{Drugs}

The use of thyroid for myxoedema has already been discussed. In other obese states its administration may cause some loss of weight owing to a diuretic action and to slight elevation of the metabolic rate. In general the drug is disappointing, and unpleasant tachycardia may be induced by its use.

Dexamphetamine sulphate has a pronounced action in causing loss of weight. Its main effect is to reduce or abolish appetite. A dose of $5 \mathrm{mg}$. should be taken half an hour before breakfast and luncheon, and at 4 p.m. It should not be taken later, as it is apt to cause insomnia. The loss of weight is not entirely due to effect on appetite, because it is seen on a fixed calorie intake. The anti-obesity effect gradually wears off and will be negligible at the end of three months. It is not suitable for elderly people or for those with cardiovascular or cerebral diseases.

How many students are there in Britain, and what are they studying? A recent publication of the University Grants Committee, for the academic year 1948-9, shows a total of 83,690 full-time students: this figure includes 2,589 from foreign countries and a further 3.335 from the British Commonwealth. They are distributed among the various faculties as follows: medicine $16.8 \%$, dentistry $3.1 \%$, pure science $19.2 \%$, technology $13 \%$, arts $44.4 \%$. Full-time teaching staff totalled 7,390. The total expenditure for the year was $f 18.022,094$, the income being nearly $60 \%$ by Parliamentary grant, $20 \%$ from fees, $5 \%$ from local authority grants, $6.7 \%$ by endowments, and $1.9 \%$ from donations and subscriptions. It is interesting to compare the size of the Parliamentary grant in $1932-3(£ 1,680,000)$ with that for the current year, $1950-1$, which is $£ 23,284,150$, to appreciate the growth of university education and facilities.

\section{SMALLPOX}

On January 26 Professor A. W. Downie delivered a special University of London, lecture at the London School of Hygiene and Tropical Medicine on "Infection and Immunity in Smallpox," a subject which the Brighton epidemic makes very topical.

In considering the pathogenesis of the disease it was not possible to speak dogmatically about many stages in its development. The disease was too severe to permit experiments with human volunteers, and, although recently Dr. Fenner had accumulated much exact information about mousepox, this laboratory model could at best only provide analogies. Therefore in discussing smallpox one must still be content to speak of probabilities.

\section{Path of Infection}

In man infection normally occurred through the respiratory tract, but whether or not there was a primary lesion was unknown. In mousepox the infection occurred through the skin and the primary lesion was visible. Manifest variola lesions in the upper respiratory tract and in the mouth were quite commonly seen in man during the stage of efflorescence, so that the failure to observe a primary lesion suggested that it was either very inconspicuous or situated in an inaccessible part of the respiratory tract. After infection there was an incubation period of 11-14 days before there were any signs of illness. If generalized disease occurred after variolation (inoculation with variola virus) the incubation period was often two to three days shorter than this, and the same was seen in infants infected congenitally.

What became of the virus during the incubation period was a matter for conjecture. From analogy with mousepox the virus probably found its way very rapidly to the local lymph nodes, where it multiplied: indeed, in variola the local lymph nodes might well be the primary focus, the mucous membrane of the respiratory tract merely allowing entry to the virus but not its multiplication. After multiplication in the regional lymph nodes there was probably a mild viraemia, with spread of the virus throughout the body. The virus was quickly removed from the blood stream by phagocytic cells and continued to multiply mainly in the liver, spleen, and bone marrow. Although the evidence was not conclusive, Professor Downie suggested that the lungs might also be a site of multiplication at this stage.

The incubation period terminated with a second viraemia, much more massive than the first. (In instances of congenital infection the baby became infected at the time of the mother's massive secondary viraemia). At this point the clinical illness might be said to begin, though the skin rash did not appear for another one or two days. During the whole of the incubation period and up to the time of the appearance of the rash, there was good evidence that the patient was not infective. Where contacts had been allowed freedom of movement no secondary cases had resulted from such contacts incubating the disease. If smallpox were, like influenza, highly infectious from the onset of illness control of outbreaks by our present policy of isolation of cases and vaccination of contacts would be very difficult.

\section{The Immune Response}

After the appearance of the skin rash the course of the disease was dominated by the immunity response and the development of antibodies. These could be measured in three ways: by a neutralization technique using the method of inoculation on the chorio-allantoic membrane of chick embryos, by a haemagglutinin-inhibition test, and by the less sensitive complement-fixation technique.

After vaccination antibodies could first be demonstrated in 10-12 days, and they reached their peak in 20 days. Thereafter their demonstration depended upon which test was used for their detection. By the neutralization test, antibodies might be detectable for 40 years or more, though 